OPEN

SUBJECT AREAS:

ORIGIN OF LIFE

PALAEONTOLOGY

PALAEOECOLOGY

VISUAL SYSTEM

Received

26 June 2013

Accepted

6 September 2013

Published

25 September 2013

Correspondence and requests for materials should be addressed to

F.C.Z. (fczhao@ nigpas.ac.cn) or M.Y.Z. (myzhu@ nigpas.ac.cn)

\section{Complexity and diversity of eyes in Early Cambrian ecosystems}

\author{
Fangchen Zhao ${ }^{1,2}$, David J. Bottjer ${ }^{2}$, Shixue Hu ${ }^{3}$, Zongjun Yin' \& Maoyan Zhu'
}

\begin{abstract}
'State Key Laboratory of Palaeobiology and Stratigraphy, Nanjing Institute of Geology and Palaeontology, Chinese Academy of Sciences, Nanjing 210008, China, ${ }^{2}$ Department of Earth Sciences, University of Southern California, Los Angeles, California 90089, USA, ${ }^{3}$ Chengdu Institute of Geology and Mineral Resources, Chengdu Center of China Geological Survey, Chengdu 610081, China.
\end{abstract}

Here we report exceptionally preserved non-biomineralized compound eyes of a non-trilobite arthropod Cindarella eucalla from the lower Cambrian Chengjiang Lagerstätte, China. The specimen represents the oldest microanatomical evidence confirming the occurrence of highly developed vision in the early Cambrian, over 2,000 ommatidia in each eye. Moreover, a quantitative analysis of the distribution of eyes related to life habit, feeding types, and phyla respectively, from the Chengjiang biota indicates that specimens with eyes mostly belong to the arthropods, and they usually were actively mobile epifaunal and nektonic forms as hunters or scavengers. Arthropods took the lead in evolution of 'good vision' and domination in Cambrian communities, which supports the hypothesis that the origin and evolution of 'good vision' was a key trait that promoted preferential diversification and formed the foundation of modern benthic ecosystems in the early Cambrian ocean.

$\mathrm{T}$ he pervasiveness, intricacy, and complexity of animal eyes has long attracted the attention of scientists. The diverse types of extant eyes reflect the selective advantages of using light as a source of information throughout evolution ${ }^{1}$. It is largely accepted that proper vision originated in the early Cambrian during the initial radiation of many animal groups $s^{2-4}$, known as the Cambrian explosion ${ }^{5-7}$. The evolution of powerful vision has been proposed as a trigger for the Cambrian explosion of animals ${ }^{8,9}$. However, the evolutionary origin and diversity of types of eyes still remains obscure. The record of early eyes is exceptionally sparse because most eyes are composed of soft tissue that does not usually fossilize, so much detail has been lost in mud and deep time. The availability of Cambrian Konservat-Lagerstätten ${ }^{5,10,11}$ with exceptional preservation offers the possibility to shed new light on the origin of eyes. The occurrence of eyes within the Chengjiang biota (approximately 520 million years ago) shows a remarkable variety of visual systems, which represent the earliest eyes in the metazoan fossil record ${ }^{10-14}$. More than 230 animal species have been described in the Chengjiang biota, representing at least 18 animal phyla and a variety of taxonomically enigmatic form $\mathrm{s}^{15}$, including primitive vertebrates ${ }^{16}$, which have great potential for understanding origination and evolution of visual systems in different animal phyla and their influence on the development of ecological communities in deep time. Here we report exceptionally preserved non-biomineralized eyes, preserved together with the body, of a non-trilobite arthropod Cindarella eucalla $a^{10,17}$ from the early Cambrian Chengjiang biota, revealing the detailed structures of compound eyes. Together with a quantitative analysis of the distribution of eyes related to life habit, feeding types, and phyla, based on abundance data collected from a Chengjiang biota locality, we then explore the evolution of vision and its influence on ecological communities in the early Cambrian ocean.

Specimens of exceptionally preserved Cindarella eucalla with eyes as well as abundance data of the Chengjiang biota (86 species, 9941 individuals) were collected from a single quarry during study of a narrow stratigraphic interval from the lower Cambrian Maotianshan Shale in the Mafang section (N 24 $46^{\prime}$, E 102 $35^{\prime}$ ), Haikou, Yunnan Province, China, where one of the richest Chengjiang fossil deposits exists ${ }^{18}$. The fossils at the Mafang section feature an abundance and diversity of well-preserved soft-bodied animals that were subjected to limited or no pre-burial transportation and limited post-burial decay ${ }^{18}$. These fossils therefore present a record of the living soft-bodied animal community and provide unparalleled materials for understanding community paleoecology in the early Cambrian. In this abundance data analysis, we focus on the quantitative distribution of eyes and their relationship to phyla and ecological groups. For each taxon, its individual abundance and the presence/absence of macroscopic eye organs has been recorded (Supplementary Table 1). 

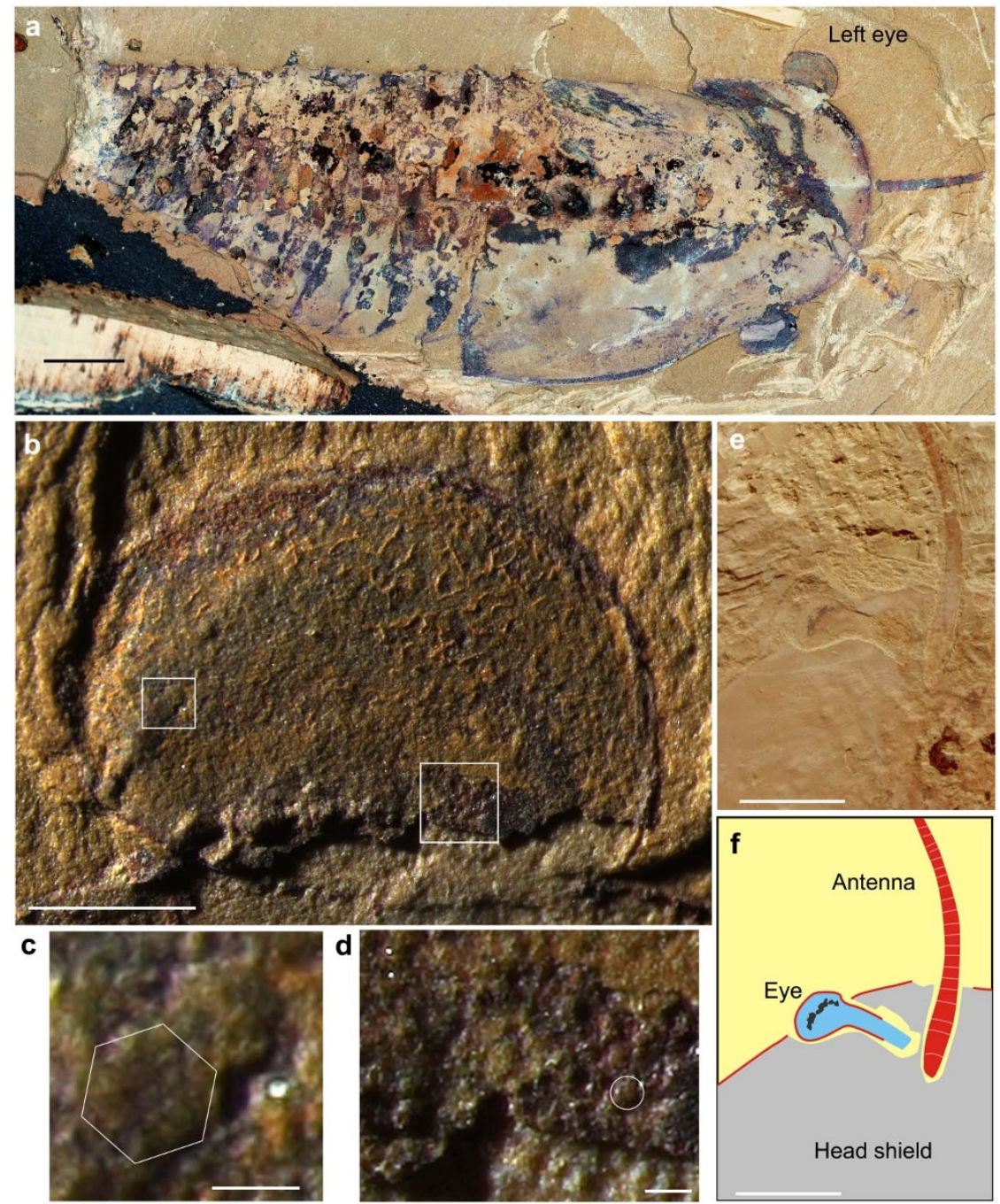

Figure 1 Cindarella eucalla from the early Cambrian Chengjiang Fauna, China. (a-d), NIGPAS 158641 from Maotianshan Shale Member at Mafang, Haikou. (a) Nearly complete specimen showing paired large eyes extending anterolaterally beyond the margin of cephalic shield. (b) Overview of left eye showing the positions of close-ups in (c) and (d). (c) Relatively large ommatidial lens arranged anterolaterally on eye, forming a light-sensitive bright zone. Hexagon indicates a large ommatidial lens with possible faint hexagonal facet. (d) Relatively small lens close to the inner margin of eye. Circle indicates a lens. (e), (f) Anterior part photograph and interpretative drawing of specimen ELRC18503 from Maotianshan, Chengjiang, detail of left eye showing stalk beneath head shield. Scale bar: (a), (g), (h) $5 \mathrm{~mm}$; (b) $1 \mathrm{~mm}$; (c), (d) $100 \mu \mathrm{m}$; (e), (f) $50 \mu \mathrm{m}$.

\section{Results}

Cindarella eucalla is represented by a relatively small number of specimens ( 7 individuals from the collection, $0.07 \%$ ), but it was discovered at various sites in the geographical region ${ }^{19}$. Fossils of Cindarella eucalla are commonly preserved dorsoventrally flattened (Fig. 1a), the exoskeleton lacked mineralization and the body is divided into a head and trunk. The head is covered by a large, semi-circular head shield, with overlap of the anterior six trunk segments by its posterior, carapace-like extension. The trunk is composed of 21-23 segments, with fewer tergites than biramous appendages. Posterior tergites are not lengthened relative to anterior ones and a median ridge extends into the terminal spine on the posterior three trunk tergites ${ }^{10,17}$ (Figs. 1, 2). The body size of Cindarella is usually $5-13 \mathrm{~cm}$ long excluding appendages. The body of Cindarella is thus extremely simple, with no obvious tagmosis, yet it exhibits developed sensory systems. The head region shows a pair of large, stalked ventral eyes that originate near the front of the lateral and anterior margins of the hypostome and extend lateroanteriorly beyond the frontal margin of the head shield, as do the long antennae (Figs. 1e, f, 2). In the well-preserved eye specimens (NGPAS 158641), the eye is globular, ovoid in outline, positioned at anterolateral margin of the head shield, usually partly beneath the head shield but entire visual surface was capable of rotation outside the head shield (Fig. 1a). In Fig. 1a, the visual surface is indicated by consistent darker colouration of the outer region of the eye, the eyes are preserved flattened, so we can only observe half of the visual surface. The ovoid visual surface has a long axis diameter of about $3.8 \mathrm{~mm}$ with a very large number of ommatidial lenses. A thin film overlying the eye indicates the presence of an eye exocuticle, the film shows wrinkles and tears indicating the soft tissue shrank during initial burial (Fig. 1b). The detailed morphology of ommatidial lenses can be observed in the left eye, the size of lenses ranges from $\sim 60$ $140 \mu \mathrm{m}$, and the larger lenses $(140 \mu \mathrm{m})$ are concentrated in the region nearest the outside margins (Fig. 1b, c), with size decreasing to almost half $(\sim 70 \mu \mathrm{m})$ towards the proximal stalk. Lens size is further reduced to about $60 \mu \mathrm{m}$ at the extreme proximal stalk (Fig. 1b, d), and extrapolating from the regions with the best preserved lenses across the area of the visual surface of the eye in Fig. 1d indicates that more than 1,000 lenses are estimated to be present on one side of the eye, so at least 2000 ommatidial lenses occur on the entire surface of these eyes. The larger lenses indicate a distinct 'bright zone $\mathrm{e}^{\text {20-22 }}$, where the visual field is sampled with higher light 


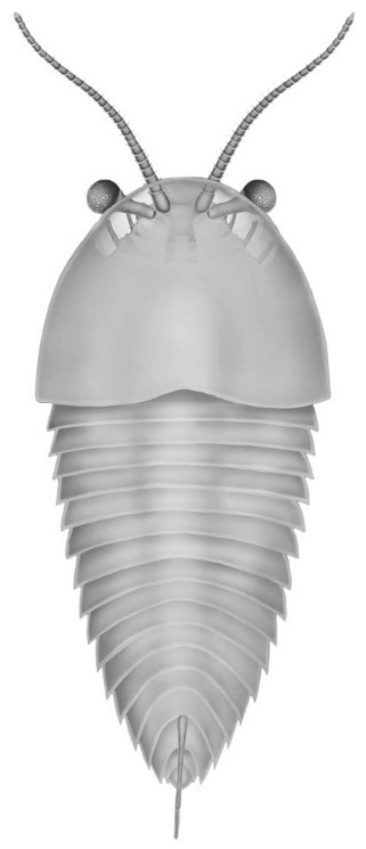

Figure $2 \mid$ Reconstruction of Cindarella eucalla in dorsal view. Paired large stalked compound eyes exposed in a cutaway view in the anterior part of cephalic shield, showing the position of sophisticated sensory organ eyes and antennae.

sensitivity due to large ommatidia. The eyes sit on stalks, capable of free movement, covered dorsally by a small palpebral lobe ${ }^{23}$. The visual field of the eyes is virtually spherical. This means that the acceptance angles of the eyes are huge, which is sufficient to cover virtually the entire field of view, and also probably was used to image objects in space due to the numerous ommatidia. The size of ommatidial lenses is initially presumed equal, about $80 \mu \mathrm{m}^{23}$. Then, the new fossil evidences indicate the varying diameters of the lenses and the existence of a bright zone. The visual surfaces of the eye reported here are similar to isolated eyes from the younger Emu Bay Shale of South Australia $^{22}$. The lenses of the ommatidia exhibit similar sizes and a bright zone. The Emu Bay eye fossils were described as previously shed corneas. Complete eyes attached to intact organisms have not been found in the Emu Bay Shale. This discovery of these Cindarella eyes may provide clues for the animal that hosted these isolated eyes from the Emu Bay Shale.

The quantitative distribution of eyes and their relationship to phyla and ecological groups was analyzed based on abundance data (86 species, 9941 individuals). A total of 31 species possess eyes, or $36 \%$ of all the collected species and $34.7 \%$ (3452) of the specimens. The specimens possessing eyes belong to arthropods (28 species), lobopods (2 species) and mollusks (1 species) (Supplementary Table 2); the arthropods dominate this eyes data set, constituting $90.3 \%$ (28) of the species and $99.7 \%$ (3440) of the specimens (Supplementary Table 3). Arthropods also are the most diverse and abundant (species: $45 \%$, individuals: $44 \%$ ) in this entire data set (Fig. 3). Based on life habit categories, the 31 species possessing eyes are identified as epifaunal vagrant (22 species), nektonic (6 species) and pelagic ( 3 species). Obviously the epifaunal vagrants dominate this eyes data set, constituting 71\% (22) of the species and $90.3 \%$ (3116) of the specimens (Supplementary Table 3). Species from this data set that are nektonic or pelagic are few, however, the relative proportion of species possessing eyes is high. These data show the proportion of species possessing eyes relatively increases from benthic to nektonic and pelagic ecospace. The proportions of species are from $53.7 \%$ (epifaunal vagrant) to $60 \%$ (nektonic) and $75 \%$ (pelagic), and the proportions of specimens are $74.8 \%$ (epifaunal vagrant) to $93 \%$ (nektonic) and 54\% (pelagic) respectively (Fig. 3; Supplementary Table 2). The proportions of specimens possessing eyes in the Mafang section are similar with previously published abundance data collected from the Shankou section $(62.8 \%$ of mobile epifaunal specimens possess eyes, and $94.5 \%$ of nektonic specimens possess eyes $)^{24}$. Based on feeding type categories, the 31 species with eyes are mostly identified as hunters/scavengers (species: $87.1 \%$, individuals: $96.7 \%$ ) (Supplementary Table 3). The data shows specimens with eyes mostly belong to arthropods and they usually were actively mobile epifaunal and nektonic forms as hunters or scavengers.

The eyes of Cindarella eucalla specimens described here represent the oldest microanatomical evidence that these early arthropods possessed advanced stalked grand compound eyes, each with over 2,000 ommatidia, which enabled high image resolution and wideangle range of vision. This arthropod was thus capable of finding food in low light, and even more important, it was able to observe and avoid predators (e.g., Anomalocaris, the giant Cambrian predator ${ }^{25}$ ), which indicates a greatly increased 'arms race' in early Cambrian food webs ${ }^{6,8,9}$. These new fossils reveal that some of the earliest arthropods had already acquired visual systems that might be similar to those of living forms, underscoring the speed and magnitude of evolutionary innovations that occurred during the Cambrian explo$\operatorname{sion}^{22}$. The quantitative analysis of the distribution of eyes related to life habit, feeding types, and phyla, respectively, indicates that the species with eyes usually were actively mobile forms as hunters or scavengers. The arthropods took the lead in evolution of 'good vision', which might have triggered arthropod diversity and domination in early Cambrian oceans. This supports the hypothesis that the origin and evolution of 'good vision' was a key trait that promoted preferential diversification ${ }^{26}$ and formed the foundation of modern benthic ecosystems in the early Cambrian ocean.

\section{Discussion}

When one traces eyes back through the fossil record, the oldest ones date back to the early Cambrian ${ }^{27}$. Despite the molecular data indicating an earlier origin of animals, the first generally accepted macroscopic fossils of bilaterian animals range in age from 565 to 550 million years old ${ }^{28}$, and these animals seem to have been much simpler. Eyes are hard to identify from any fossil remains of Precambrian organisms. But something remarkable seems to have happened at the interface between the Precambrian and the Cambrian, because after then animal diversification appears to have accelerated dramatically from 535 to 525 million years ago. Eyes can be identified in Cambrian exceptionally-preserved fossils. Especially, fossils from the Chengjiang biota present an extremely interesting set of examples in which to examine visual development through all phyla (Fig. 4). Compound eyes that occur in numerous arthropod taxa have been described, such as Leanchoilia ${ }^{29}$, Fuxianhuia ${ }^{13}$ and Isoxys ${ }^{14}$. Large compound eyes are, of course, a distinctive feature of the stem arthropod Anomalocaris ${ }^{25,30}$. Within the lobopodians, Hallucigenia and Luolishania might have had a simple type of visual system, such as eyespots $^{31}$ or primitive compound eyes ${ }^{12}$. Nectocaris (Petalilium), which is interpreted as an early cephalopod, may have possessed camera-type eyes ${ }^{32}$. The earliest vertebrate, Haikouichthys, from this biota also bears eyes ${ }^{16}$. The available fossil record illustrates that the Cambrian explosion spawned the simultaneous birth of the principal invertebrate compound eye and the vertebrate camera-style eye. These eyes usually are just visible as dark imprints with no detailed structures preserved. This report on the compound eyes of Cindarella, showing the large size of ommatidial lens facets (60$140 \mu \mathrm{m}$, Fig. 1b, c) and a large number of ommatidia (over 2000), indicates that it had extraordinary vision similar to that of living forms. Although we cannot know exactly how much organization in cellular function or morphology occurred in the Cambrian, this extraordinary visual surface confirms the occurrence of highly 

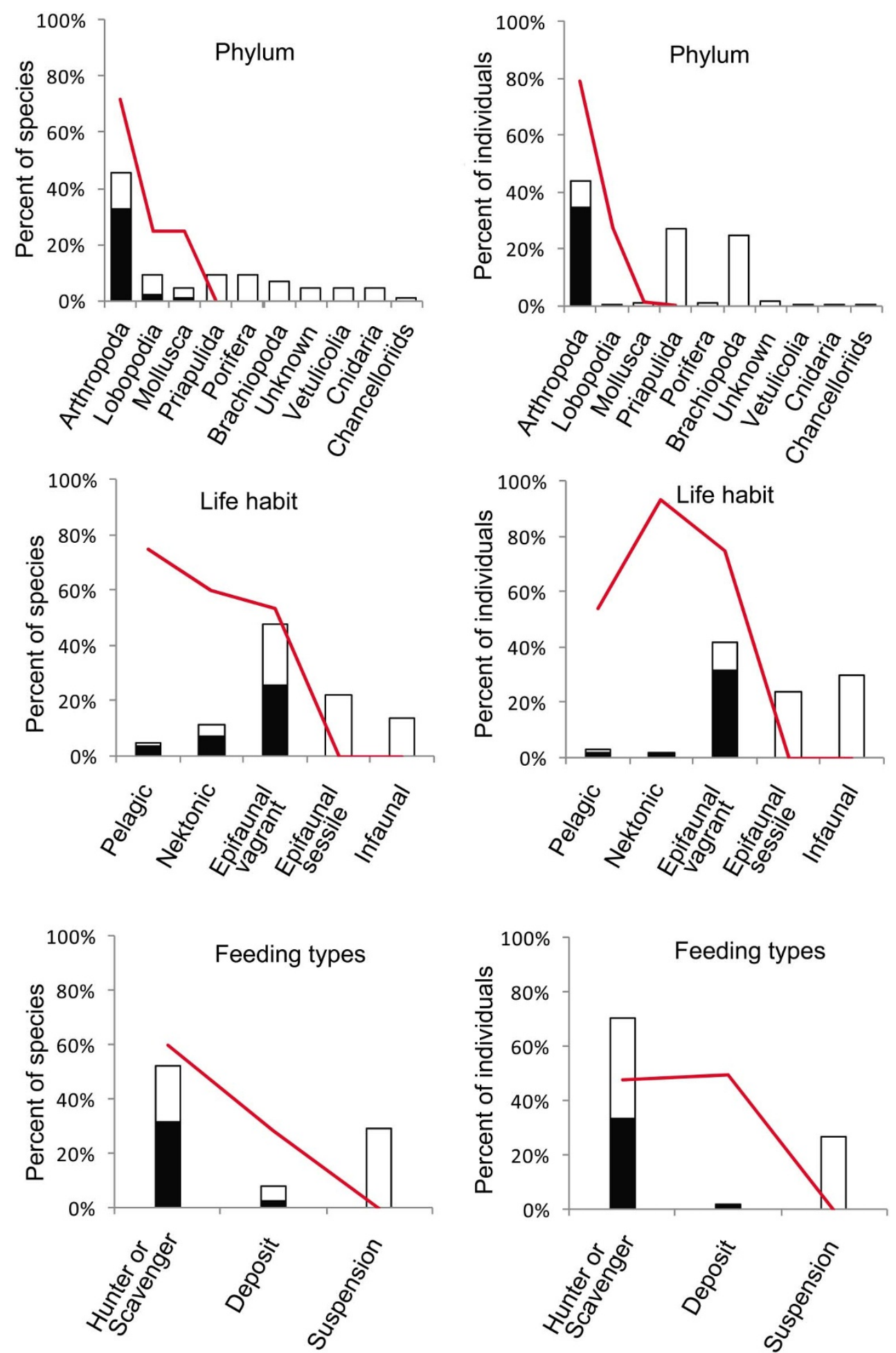

Figure $3 \mid$ Summary of the percentage of species and specimens possessing eyes, related to phylum, life habit and feeding types respectively. The histograms represent all the specimens collected, the black color in the histograms indicates the specimens possessing eyes. The red line indicates the proportion of specimens with eyes in respective categories.

developed vision in the early Cambrian. Compound eyes seem to have evolved much more rapidly than other eye-types, from eyespots to complicated, advanced eyes, especially in arthropods. A monophyletic origin of the metazoan eye is strongly supported since Pax6 is involved in eye development in all bilaterian phyla ${ }^{33}$. If the metazoan eye is indeed monophyletic, then the time required for a simple eye to evolve within these different eye-types might be remarkably short. This hypothesis has been tested using a conceptual model involving a linear series of eyes, arranged from simple to complex, and as mathematically predicted by Nilsson and Pelger ${ }^{34}$, a patch of light-sensitive epithelial tissue could evolve by natural selection into a camera eye within only about 364000 generations, in other words in less than half a million years. Thus compound eyes show the quickest rate of evolution during the early stages of eye evolution as the fossil record shows that evolution of the eye into a highly advanced compound eye was amazingly rapid ${ }^{22,30,35-37}$. The fossil 

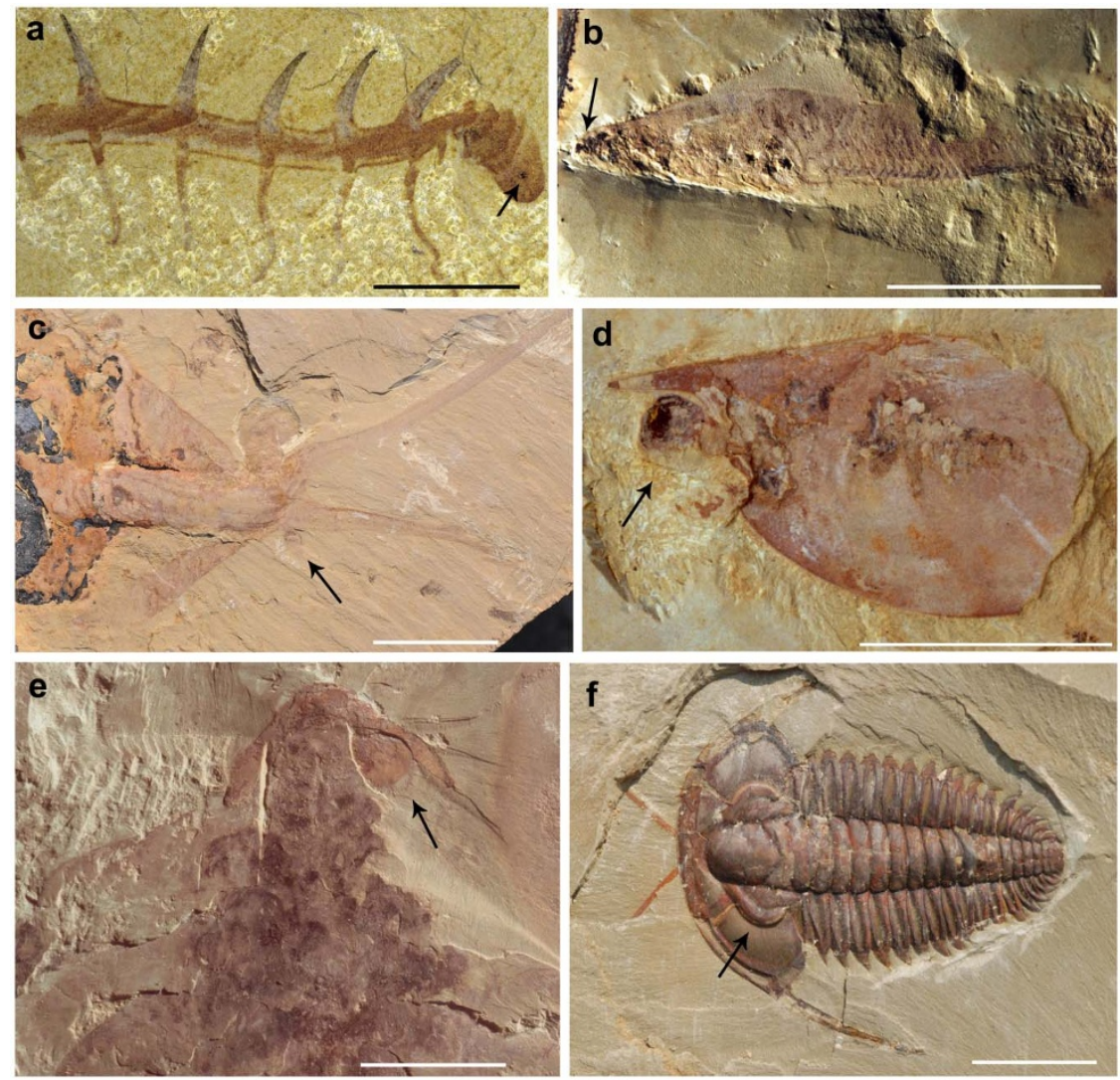

Figure 4 | Examples of Cambrian eyes within metazoan phyla from the Chengjiang Fauna. The eyes are indicated by an arrow. (a) Lobopod Hallucigenia fortis (RCCBYU 10248, YU) has a pair of sessile eyes composed of at least two visual units (ommatidia), interpreted as pigment cups ${ }^{12}$. (b) Vertebrate Haikouichthys ercaicunensis (HZ-f-12-127, YGSK) has a pair of eyes identified by Shu et al. ${ }^{16}$. (c) Mollusc Petalilium latus (158642, NIGPAS) with two camera-type eyes, which are attached by short stalks to the latero-ventral surface of the head ${ }^{32}$. (d) Bivalved arthropod Isoxys auritus with a pair of large eyes, projecting from the body and showing a flexible eye-stalk, the ommatidial lens distinguished by Schoenemann and Clarkson ${ }^{14}$. (e) Cambrian apex predator Anomalocaridids Amplectobelus sumbrachiata (ELRC 21002, NIGPAS) supposedly has a pair of enormous compound eyes with acute vision ${ }^{30}$. (f) Trilobite Eoredlichia intermedia (158643, NIGPAS) eyes typically sessile, crescentic, with inflated palpebral lobe ridges running toward front of glabella. Scale bars: (a) $5 \mathrm{~mm}$; (b-f) $1 \mathrm{~cm}$. [Panel (a) courtesy of X.-G. Hou, Yunnan University, Kunming, China (YU); panel (b) courtesy of H.-L. Luo, Yunnan Institute of Geological Sciences, Kunming, China (YGSK); panel (c), (d), (e), (f) are from Nanjing Institute of Geology and Palaeontology, China (NIGPAS).]

record also indicates that image-forming eyes possessing a high resolution image probably evolved first in the arthropods due to the numerous ommatidia. In most phyla, although simple photoreception is almost universally present, no visional eyes evolved, although eyes evolved later in Annelida, Onychophora, Mollusca, and Chordata.

In the modern, image-forming eyes occur in 6 of the 33 extant metazoan phyla (Cnidaria, Mollusca, Annelida, Onychophora, Arthropoda, and Chordata), and these six contribute about $96 \%$ of the known species alive today ${ }^{2}$. It is not hard to appreciate the enormous competitive value of good vision. This good vision would have allowed for expansion of ecological niches and dispersal ability ${ }^{8,9}$. Many compound eyes of arthropods are particularly notable for their exceptionally wide field of view and often high sensitivity to motion $^{38}$. In the Cambrian, these developed compound eyes allowed Cindarella eucalla to easily detect prey and also to detect danger, such as Anomalocaris, a grand predator, when it moved close by. This indicates that these organismal interactions greatly increased competition pressure and the 'arms race' due to this extraordinary vision development ${ }^{8,9}$. This developed vision also indicates significant evolution of the overall nervous system, requiring decisions to be made rapidly and accurately. Compound eyes with increasing number and size of ommatidia allowed arthropods to be able to resolve spatial information, which arguably is the most important visual quality of eyes. Those taxonomic groups possessing the evolutionary advantage of vision became diverse and abundant, which is a reason why the arthropods are dominant in animal communities in the Cambrian. The proportion of arthropods in the early Cambrian Chengjiang are $45 \%$ of species and $44 \%$ of individuals and for the middle Cambrian Burgess shale are $43 \%$ of species and $60 \%$ of individuals $^{39}$. Fossil specimens with eyes mostly belong to arthropods thus supporting the hypothesis that good vision triggered arthropod diversity and domination in early Cambrian ecosystems, and origin and evolution of good vision formed the foundation of modern benthic ecosystems in early Cambrian oceans.

\section{Methods}

Fossils were photographed with a Nikon D300s fitted with a Nikon AF-S Micronikkor $105 \mathrm{~mm}$ lens (Figs. 1a, e, 4c-f). Close-up images of fossil eyes were taken using the Zeiss Discovery V20 microscope system, under low angle fiber optic directional illumination from the top to enhance the relief of the compressed fossil (Fig. 1b-d). The figures were prepared with Adobe Photoshop CS4 and Coral Draw X4. For the abundance data analysis, taxa were assigned to phyla and ecological groups according to biological categories, life habits and feeding types, Life habits are assigned to four categories, infaunal, epifaunal, nektobenthic or pelagic; infaunal and epifaunal habits may be further characterized as either sessile or vagile. Feeding types are categorized in three groups, namely, suspension feeding, deposit feeding, hunting/scavenging. Each taxon, its individual abundance and the presence/absence of macroscopic eye organs has been recorded and counted in these categories. The statistical data are provided in the Supplementary Tables 1-3. These materials are deposited in the Nanjing Institute of Geology and Palaeontology. 
1. Goldsmith, T. H. Optimization, constraint, and history in the evolution of eyes. Q. Rev. Biol. 65, 281-322 (1990).

2. Land, M. F. \& Nilsson, D. E. Animal eyes (Oxford Univ. Press, 2002).

3. Schwab, I. R. Evolution's Witness: how eyes evolved (Oxford Univ. Press, 2012).

4. Peterson, K. J. et al. Estimating metazoan divergence times with a molecular clock. Proc. Natl Acad. Sci. USA 101, 6536-6541 (2004).

5. Briggs, D. E. G., Erwin, D. H. \& Collier, F. J. The fossils of the Burgess Shale (Smithsonian Institution Press, 1994).

6. Marshall, C. D. Explaining the "Cambrian Explosion" of animals. Annu. Rev. Earth Planet. Sci. 34, 355-384 (2006).

7. Conway Morris, S. Burgess Shale Faunas and the Cambrian Explosion. Science 246, 339-346 (1989)

8. Parker, A. In the Blink of an Eye: How Vision Sparked the Big Bang of Evolution. (Basic Books, 2003).

9. Parker, A. R. Colour in Burgess Shale animals and the effect of light on evolution in the Cambrian. Proc. R. Soc. B 265, 967-972 (1998).

10. Chen, J. Y. \& Zhou, G. Q. Biology of the Chengjiang fauna. Bulletin of the National Museum of Natural science 10,11-106 (1997).

11. Hou, X. G. et al. The Cambrian Fossils of Chengjiang, China: The Flowering of Early Animal Life (Blackwell, 2004).

12. Ma, X. Y. et al. Morphology of Cambrian lobopodian eyes from the Chengjiang Lagerstätte and their evolutionary significance. Arthropod Struct. Dev. 41, 495-504 (2012).

13. Ma, X. Y., Hou, X. G., Edgecombe, G. D. \& Nicholas, J. S. Complex brain and optic lobes in an early Cambrian arthropod. Nature 490, 258-262 (2012).

14. Schoenemann, B. \& Clarkson, E. N. K. Eyes and vision in the Chengjiang arthropod Isoxys indicating adaptation to habitat. Lethaia 44, 223-230 (2011).

15. Zhao, F. C., Zhu, M. Y. \& Hu, S. X. Community structure and composition of the Cambrian Chengjiang biota. Sci. China Earth Sci. 53, 1784-1799 (2010).

16. Shu, D. G. et al. Lower Cambrian vertebrates from South China. Nature 402, 42-46 (1999).

17. Ramsköld, L., Chen, J. Y., Edgecombe, G. D. \& Zhou, G. Q. Cindarella and the arachnate clade Xandarellida (Arthropoda, Early Cambrian) from China. T. Roy. Soc. Edin.-Earth 88, 19-38 (1997).

18. Zhao, F. C., Caron, J. B., Hu, S. X. \& Zhu, M. Y. Quantitative analysis of taphofacies and paleocommunities in the Early Cambrian Chengjiang Lagerstätte. Palaios 24, 826-839 (2009).

19. Zhao, F. C. et al. Spatial variation in the diversity and composition of the Lower Cambrian (Series 2, Stage 3) Chengjiang biota, Southwest China. Palaeogeogr. Palaeoclimatol. Palaeoecol. 346, 54-65 (2012).

20. Van Hateren, J. H. et al. The bright zone, a specialized dorsal eye region in the male blowfly Chrysomyia megacephala. J. Comp. Physiol. A 164, 297-308 (1989).

21. Straw, A. D., Warrant, E. J. \& O'Carroll, D. C. A. "bright zone" in male hoverfly (Eristalis tenax) eyes and associated faster motion detection and increased contrast sensitivity. J. Exp. Biol 209, 4339-4354 (2006).

22. Lee, M. S. Y. et al. Modern optics in exceptionally preserved eyes of Early Cambrian arthropods from Australia. Nature 474, 631-634 (2011).

23. Schoenemann, B. \& Clarkson, E. N. K. At first sight - Functional analysis of Lower Cambrian eye systems. Palaeontographica A 297, 123-149 (2012).

24. Plotnick, R. E., Dornbos, S. Q. \& Chen, J. Y. Information landscapes and sensory ecology of the Cambrian Radiation. Paleobiology 36, 303-317 (2010).

25. Chen, J. Y., Ramsköld, L. \& Zhou, G. Q. Evidence for monophyly and arthropod affinity of Cambrian giant predators. Science 264, 1304-1308 (1994).

26. Aberhan, M., Nürnberg, S. \& Kiessling, W. Vision and the diversification of phanerozoic marine invertebrates. Paleobiology 38, 187-204 (2012).

27. Zhang, X. G. \& Clarkson, E. N. K. The eyes of Lower Cambrian eodiscid trilobites. Palaeontology 33, 911-932 (1990).
28. Narbonne, G. M. The Ediacara biota: Neoproterozoic origin of animals and their ecosystems. Annu. Rev. Earth Planet. Sci. 33, 421-442 (2005).

29. Schoenemann, B. \& Clarkson, E. N. K. The eyes of Leanchoilia. Lethaia 45 , 524-531 (2012)

30. Paterson, J. R. et al. Acute vision in the giant Cambrian predator Anomalocaris and the origin of compound eyes. Nature 480, 237-240 (2011).

31. Schoenemann, B. et al. A miniscule optimized visual system in the Lower Cambrian. Lethaia 42, 265-273 (2009).

32. Smith, M. R. \& Caron, J. B. Primitive soft-bodied cephalopods from the Cambrian. Nature 465, 427-428 (2010).

33. Gehring, W. J. Chance and necessity in eye evolution. Genome Biol. Evol. 3, 1053-1066 (2011).

34. Nilsson, D. E. \& Pelger, S. A pessimistic estimate of the time required for an eye to evolve. Proc. R. Soc. B 256, 53-58 (1994).

35. Schoenemann, B. et al. The sophisticated visual system of a tiny Cambrian crustacean: analysis of a stalked fossil compound eye. Proc. R. Soc. B 279, 1335-1340 (2012).

36. Clarkson, E. N. K., Levi-Setti, R. \& Horváth, G. The eyes of trilobites: The oldest preserved visual system. Arthropod Struct. Dev. 35, 247-259 (2006).

37. Schoenemann, B. \& Clarkson, E. N. K. Discovery of some 400 million year-old sensory structures in the compound eyes of trilobites. Sci. Rep. 3, 1429 (2013).

38. Warrant, E. \& Nillson, D. E. Invertebrate Vision Ch. 1 (Cambridge Univ. Press, 2006).

39. Caron, J. B. \& Jackson, D. A. Paleoecology of the Greater Phyllopod Bed community, Burgess Shale. Palaeogeogr. Palaeoclimatol. Palaeoecol. 258, 222-256 (2008).

\section{Acknowledgements}

This work was supported by the Chinese Academy of Sciences (KZCX2-EW-115, KZZD-EW-02-2), the National Basic Research Program of China (2013CB835006), the National Natural Science Foundation of China (40930211, 41002002, J1210006) and the Natural Science Foundation of Jiangsu Province (BK2012893).

\section{Author contributions}

All authors contributed directly to interpretation of fossil specimens, analysis and writing the paper. F.C.Z. designed the study and made statistics of these fossils. F.C.Z. and S.X.H. collected and prepared specimens. F.C.Z., S.X.H. and Z.J.Y. conducted the observations and photography of specimens, prepared figures and the earlier manuscript. D.J.B. and M.Y.Z. corrected the English and improved the final manuscript.

\section{Additional information}

Supplementary information accompanies this paper at http://www.nature.com/ scientificreports

Competing financial interests: The authors declare no competing financial interests.

How to cite this article: Zhao, F., Bottjer, D.J., Hu, S., Yin, Z. \& Zhu, M. Complexity and diversity of eyes in Early Cambrian ecosystems. Sci. Rep. 3, 2751; DOI:10.1038/srep02751 (2013).

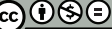

This work is licensed under a Creative Commons Attribution-

NonCommercial-NoDerivs 3.0 Unported license. To view a copy of this license visit http://creativecommons.org/licenses/by-nc-nd/3.0 